\title{
Management of Warfarin Therapy: A New Point-Of-Care Monitoring Service by Community Pharmacists in India
}

\author{
Deepalakshmi M, Christy Joseph, Carolyne Jacob, Arun K P, Ponnusankar S* \\ Department of Pharmacy Practice, JSS College of Pharmacy, Udhagamandalam, The Nilgiris, Tamilnadu, INDIA. \\ JSS Academy of Higher Education and Research, Mysuru, Karnataka, INDIA.
}

\begin{abstract}
Objective: To introduce the implementation of point of care INR monitoring service by community pharmacists for optimizing the therapy outcomes of Warfarin, used widely for its anticoagulant activity both as a treatment and prophylaxis. Methods: This prospective, controlled, staggered parallel design study was conducted in selected community pharmacies associated with general practitioners. The patients in the intervention arm received point of care INR measurement and anticoagulant management including assessment of clinical and quality of life endpoints by their pharmacists in collaboration with their general practitioners. Result: 82 patients were recruited into the study in 5 community pharmacies and all these patients were under the medical care of 7 general medical practitioners. About $44 \%$ $(n=36)$ of the patients recruited into the intervention group submitted their retrospective INR reports which was considered as pre intervention data and used to compare the clinical outcome against post intervention phases. It was found that the patients in the post intervention group had a statistically significant $(p<0.05)$ control in the INR values than the pre
\end{abstract}

intervention group. A statistically significant difference $(p=0.025)$ was observed in the quality of life of patients at pre and post intervention groups. There was also a significant $(p=0.016)$ increase in patient's knowledge about anticoagulant therapy between pre and post intervention. Conclusion: The community pharmacists and medical practitioners managed anticoagulant service is feasible and acceptable to patients and pharmacist involved in the study.

Key words: Community pharmacist, INR, Anticoagulant service, Quality of life, Knowledge.

Correspondence

Dr. Ponnusankar S, Department of Pharmacy Practice, JSS College of Pharmacy Ooty - 643001, The Nilgiris Tamil Nadu, INDIA.

Phone: +91-9489613428

Email: drsponnusankar@jssuni.edu.in

DOI: 10.5530/jyp.2018.10.77

\section{INTRODUCTION}

Warfarin, an important drug in cardiology is used widely for its anticoagulant activity both as a treatment and prophylaxis in pulmonary embolism and deep vein thrombosis, atrial fibrillation and myocardial infarction patients to prevent thromboembolic events. ${ }^{1}$ Despite its benefits, the use of Warfarin is more challenging and complicated by the risk associated with it use that may be even fatal in some cases apart from the excessive bleeding due to over-anticoagulation. On the other hand, the patients with treated with sub therapeutic doses of Warfarin at high risk of thrombotic events that also has serious outcomes. ${ }^{2}$

Western countries have reported the incidence of $0.2 \%$ and $0.4-1.3 \%$ intracranial haemorrhage and major bleeding respectively due to low dose Warfarin. The same was reported at a slightly higher rate of $0.6 \%$ and $2.38 \%$ in Japanese patients. ${ }^{3}$ Another audit conducted at Limerick at Health Services Executive (HSE) Mid-Western area captured an annual cumulative incidence of $16.6 \%$ haemorrhagic events in patients with INR $>$ or $=5$ Further, the incidence of $1.3 \%$ and $15.3 \%$ of major and minor haemorrhagic events were recorded over a period of twelve months in patients with INR $>$ or $=5 .{ }^{4}$ Australia had documented more than five thousand hospital admissions during 1999 - 2000 due to inappropriate dosing of Warfarin. ${ }^{5-6}$ Unfortunately no such data is available in Indian health care settings. However, when the numbers are very alarming in the developed countries, the same shall be much more than those figures in India.

As there is a remarkable interindividual variability in the pharmacokinetics and or pharmacodynamics of Warfarin and the drug has significant risk of interacting with other co-administered drugs. ${ }^{7-8}$ close monitoring and vigilance is warranted in patients treated with Warfarin.
Conventionally, International Normalised Ratio (INR) is measured and accordingly the dose titration of Warfarin is done.

Though the risk of bleeding is associated with increase in INR more than 5 , about $50 \%$ of such episodes are also reported with INR lower than $4 .{ }^{9}$ This reveals the significance of INR monitoring and patient education in avoiding serious outcomes for patients on Warfarin therapy. Further, the gradually increasing geriatric population and cardiovascular complications in India increase the size of population to receive Warfarin that will require individualization of dose to minimize the risk and incidence of serious adverse drug reaction association with Warfarin. ${ }^{10}$

It is also evident that patients on Warfarin therapy have significant impacts on their health related quality of life. ${ }^{11}$ Periodic INR assessment, continuous vigilance on diet, concomitant medications are vital for a better outcome on quality of life of such patients on Warfarin therapy. To accomplish these tasks, patients should regularly visit a biochemical laboratory and or a general practitioner for blood sample collection, INR testing and interpretation of the results, dosage adjustment respectively. This conventional practice obviously disrupts the day to day routines of patients as the time to be dedicated for these tasks too much especially in the health care scenario of India. ${ }^{12}$

In these context, this study aimed to address the concept of community pharmacists working with general practitioners providing point of care INR monitoring apart from providing education and support to patients receiving Warfarin and disseminating the reports of INR testing to the patients and their general practitioners for optimizing the dosage regimen of Warfarin. 


\section{MATERIALS AND METHODS}

This prospective, controlled, staggered parallel design study was conducted in selected community pharmacies associated with general practitioners. The patients in the intervention arm received point of care INR measurement and anticoagulant management including assessment of clinical and quality of life endpoints by their pharmacists in collaboration with their general practitioners. The patients on the control arm were to receive their conventional care. The study was approved by the Institutional Review Board. (JSSCP/DPP/IRB/07/2015-16)

Pharmacists having their practice sites attached with medical practitioners in the district where the study was conducted were sent invitations to participate in the continuing professional education (CPE) program about point of care monitoring of INR and anticoagulation therapy. The CPE program disseminated information about Warfarin therapy, significance of measuring INR routinely, dietary factors, patient information, etc. They were also given hands-on training for measuring INR at point of care. The participants were given information leaflet along with written informed consent forms to voluntarily participate in the study. Those pharmacists presented their written informed consent were recruited into the study.

The patients visited the study site pharmacies with the prescription for Warfarin and those who were referred by the treating physicians were approached to be the study participants. The other individuals visited the selected pharmacies were also approached to be the study subjects in other arms of the study. As the investigators of the study did not always get a chance to meet the patients on Warfarin and / or others visiting the study site pharmacies, the community pharmacists of the respective pharmacies were given all technical support for the recruitment process those include but not limited to information leaflet, informed consent form, training to get informed consent, etc.

As per the inclusion criteria the patients who were prescribed with Warfarin continuously for more than 3 months and others who consented to take part in the study were included in to the appropriate arms. The patients with known contraindications with Warfarin and or clotting disorders and or known hepatic and renal impairment were excluded from the study.

The study participants visited their pharmacist at least once in a month for checking their INR by using CoaguChek XS- blood INR PT monitoring test meter and/or other general health screening and patient counselling services using a standardized patient information leaflet. The patients' medical and medication history were collected in a structured patient data collection form during their first visit by the respective pharmacist and the questionnaires to assess the quality of life and knowledge on Warfarin therapy. ${ }^{13-14}$ were also administered during the same visit. During the subsequent visit of the patients, the pharmacists continued to provide the same services as required and recommended the need of dosage modifications to the physicians for necessary changes in Warfarin dosage regimen. However, the final decision on the modification of Warfarin dosage in study patients was vested with the physicians.

The collected data were posted and analysed using SPSS (Version 21). Paired student $t$ test with unequal variance (and Bonferroni correction), Wilcoxon Signed Ranks test and repeated measures analysis of variance were used appropriately with a significance level of 0.05 .

\section{RESULTS}

A total of 19 community pharmacists participated in the continuing pharmacy education program conducted as described earlier, but only 5 were able to recruit patients to the study. The patients' demographic data is presented in the (Table 1). The data showed that male patients more than thrice as many as female patients $(n=61$ and $n=21$, respectively) participated in the study and atrial fibrillation as the major indication for which Warfarin therapy is given. 82 patients were recruited into the study in 5 community pharmacies and all these patients were under the medical care of 7 general medical practitioners. Out of these 82 patients, 80 completed all the follow-ups whereas 2 withdrawn from the study.

About $45 \%(n=36)$ of the patients recruited into the intervention group submitted their retrospective INR reports which was considered as pre intervention data and used to compare the clinical outcome against post intervention phases. 28 patients were recruited into the control arm who were not monitored for INR regularly. Only knowledge assessment and quality of life assessment data were collected from control arm patients. The INR data of pre intervention phase and post intervention phase along with the descriptive statistics of these patients are given in (Table 2).

\section{DISCUSSION}

Literature supports the assessment of percentage of number of times the patient's INR value is in the target range would be the best way to evaluated the patients' outcome for Warfarin therapy, ${ }^{15}$ the same was assessed and the values are shown in Table 2. It was found that the patients in the post intervention group had a statistically significant control in the INR values than the pre intervention group. The average numbers of INR

Table 1: Demographic Characteristics of the Patients.

\begin{tabular}{ccc}
\hline & Intervention Arm & Control Arm \\
\hline Patient Nos. & 82 & 28 \\
Male/ Females & $61 / 21$ & $25 / 03$ \\
$\begin{array}{c}\text { Age (years) } \\
\text { (mean } \pm \text { SD) }\end{array}$ & $61.4 \pm 3.1$ & $63.6 \pm 2.9$ \\
$\begin{array}{c}\text { Duration of Warfarin } \\
\text { (Months) (mean } \pm \text { SD) }\end{array}$ & $41.7 \pm 6.2$ & $46.2 \pm 4.9$ \\
$\begin{array}{c}\text { Indication for } \\
\text { Warfarin }\end{array}$ & $\begin{array}{c}\text { Atrial fibrillation(49) } \\
\text { Cardiac Prosthetic }\end{array}$ & $\begin{array}{c}\text { Atrial Fibrillation (19) } \\
\text { Cardiac Prosthetic } \\
\end{array}$ \\
& $\begin{array}{c}\text { Deepveinthrombosis(6) } \\
\text { Cardiomyopathy (4) }\end{array}$ & Bypass surgery(3) \\
& Post-MI (5) & \\
& Arterial Disease (3) & \\
\hline
\end{tabular}

Table 2: Summary of clinical outcomes of pre intervention phase and post intervention phase.

\begin{tabular}{ccc}
\hline Parameter & $\begin{array}{c}\text { Preintervention } \\
\text { phase }\end{array}$ & $\begin{array}{c}\text { Post intervention } \\
\text { phase }\end{array}$ \\
\hline Patients & 36 & 44 \\
Number of INR Results & 138 & 754 \\
Number of INR results per patient & 3.8 & 17 \\
Time in study (in months) & $8.3 \pm 3.7$ & $9.4 \pm 2.8$ \\
INR value (mean \pm SD) & $2.7 \pm 0.6$ & $2.6 \pm 0.3$ \\
Percentage of INR readings & $77.53 \pm 15.83$ & $87.28 \pm 4.71^{*}$ \\
within the range & & \\
Percentage of INR readings & $9.37 \pm 3.29$ & $7.21 \pm 1.32^{*}$ \\
above the range & & \\
Percentage of INR readings & $12.78 \pm 5.19$ & $6.52 \pm 1.03^{*}$ \\
below the range & & \\
\hline
\end{tabular}

${ }^{*} \mathrm{p}$ value $<0.05$ with unpaired two tailed student $\mathrm{t}$ - test 
values those were above or below the recommended range were also found significantly $(p<0.05)$ less in the post intervention group than the pre intervention group. This revealed that the point of care INR measurement and pharmacists' counselling on Warfarin therapy resulted in a better control of INR in patients.

Semi-structured interviews with the study patients confirmed that no major (haemorrhagic and thromboembolic) or minor (episodes of bruising or bleeding) adverse drug reactions associated with Warfarin were recorded during the study. A 32- item questionnaire assessment tool was used to evaluate patients' quality of life before and after the intervention arm and using control arm in both the instances. This tool was designed to assess the quality of life in relation to anticoagulation based on the categories given in (Table 3 ).

While there was a significant difference towards betterment in all these aspects of QoL for the intervention group compared to the control group at the end of the study, as evidenced by a $p$ value of 0.025 , general psychological distress did not achieve a significant difference $(\mathrm{p}=0.102)$. Improvement achieved through patient education and counselling on patients' knowledge about Warfarin therapy was assessed and the results are shown in (Table 4).

The results showed an increased trend and statistically significant difference towards improvement in the knowledge about Warfarin therapy measured using the questionnaire in both the intervention and control patients. Both groups of patients had reasonable similar knowledge of Warfarin on entry into the study (56.84 vs. 54.47 ) but the $95 \%$ confidence interval for the change in knowledge scores showed that the patients in the intervention group displayed a larger increase during the study. This supports the observation that pharmacists used the Warfarin knowledge questionnaire to identify gaps in patient knowledge and used specific counselling to address these gaps or misconceptions. ${ }^{16}$ The pharmacists were provided with the knowledge assessment questionnaire after their enrolment into the study.

A total of 39 community pharmacists from 19 community pharmacies have participated. After collecting the filled-in knowledge assessment questionnaire, these 39 pharmacists participated in a $60 \mathrm{~min}$ specialized pharmacy education module which included (i) information about the clinical use of Warfarin with the focus on its use in the community, importance of routine monitoring, dose adjustment, dietary factors, patient education aids and drug interactions (ii) skills training in counselling patients receiving Warfarin etc.

These subjects were provided with the same questionnaire again after the module. The answers were given score and the pre-module and postmodule responses from the pharmacists were compared using pared student $t$ test. The results found that there is a significant increase in the pharmacist's knowledge towards Warfarin therapy (Table 5).

Another important aspect of this study was the role that pharmacists played in optimizing anticoagulant therapy in collaboration with medical practitioners. ${ }^{17}$ Pharmacists received training and used a dosing protocol to make recommendations for consideration by medical practitioners. In the intervention arm of this study pharmacists made a total of 58 recommendations about Warfarin management involving an alteration to therapy, in response to 754 INR measurements. The outcomes of such recommendations are summarized in (Table 6). It is evident that the recommendations for decrease in dose were widely accepted than that of the recommendations for increase in dose of Warfarin by the general practitioners. This study demonstrated that the community pharmacists and medical practitioners managed anticoagulant service was feasible and acceptable to patients and pharmacist involved in the study. Trained and supported pharmacists were able to make credible management recommendations about anticoagulation therapy. However, there are practical difficulties in executing this model as many of the pharmacies are
Table 3: Quality of life data for the intervention and Control patients in the study.

\begin{tabular}{ccccc} 
Treatment related & \multicolumn{2}{c}{ Intervention $(n=80)$} & \multicolumn{2}{c}{ Control $(n=28)$} \\
& Pre & Post & Baseline & End \\
& Mean \pm SD & Mean \pm SD & Mean \pm SD & Mean \pm SD \\
$\begin{array}{c}\text { Medical Treatment } \\
\text { Satisfaction } \\
\text { Self-Efficacy }\end{array}$ & $2.97 \pm 1.01$ & $4.98 \pm 0.92^{*}$ & $3.97 \pm 1.02$ & $4.02 \pm 1.10$ \\
$\quad$ General & $2.19 \pm 0.85$ & $2.19 \pm 0.85$ & $3.11 \pm 0.98$ & $2.99 \pm 0.64$ \\
$\begin{array}{c}\text { Psychological } \\
\text { Distress }\end{array}$ & & & & \\
$\begin{array}{c}\text { Daily Hassles } \\
\text { Strained Social }\end{array}$ & $2.27 \pm 2.12$ & $3.35 \pm 1.98$ & $3.57 \pm 1.05$ & $3.97 \pm 1.64$ \\
Network & $2.64 \pm 0.80$ & $3.15 \pm 0.64$ & $2.91 \pm 0.81$ & $2.90 \pm 0.85$ \\
\hline
\end{tabular}

${ }^{*} p<0.05$ in unpaired t-test.

Table 4: Impact of education on patient's knowledge about Warfarin therapy.

\begin{tabular}{cccc}
\hline Parameter & $\begin{array}{c}\text { Entry } \\
\text { (Pre) }\end{array}$ & $\begin{array}{c}\text { Exit } \\
\text { (Post) }\end{array}$ & $\begin{array}{c}\text { Percent Change } \\
\text { (Post-Pre) }\end{array}$ \\
\hline Intervention $(\mathrm{n}=80)$ & $56.84 \pm$ & $73.42 \pm 11.48$ & $29.16 \pm 4.31^{\star}$ \\
& 17.72 & & $(17.42-41.35)$ \\
Control(n=28) & $54.47 \pm$ & $62.31 \pm 17.28$ & $14.39 \pm 3.92$ \\
& 16.16 & & $(6.58-19.04)$ \\
\hline
\end{tabular}

Data shown as mean \pm standard deviation with $95 \%$ confidence interval in brackets. *Significantly different $(\mathrm{p}<0.05)$.

Table 5: Pharmacist's knowledge towards Warfarin therapy.

\begin{tabular}{cccc}
\hline & Pre Module & Post Module & $\begin{array}{c}\text { Percentage } \\
\text { Change }\end{array}$ \\
\hline $\begin{array}{c}\text { Pharmacist } \\
(\mathrm{n}=39)\end{array}$ & $1.35 \pm 0.07$ & $1.83 \pm 0.74$ & $\begin{array}{c}35.55 \pm 5.72^{* * *} \\
(22.41-49.36)\end{array}$ \\
\hline
\end{tabular}

Data shown as mean \pm standard deviation with $95 \%$ confidence interval $(\mathrm{p}<0.001)$.

Table 6: Acceptance rate for the recommendations of pharmacists by the general practitioners.

\begin{tabular}{cccc}
\hline Recommendation & $\begin{array}{c}\text { Pharmacist } \\
\text { Recommendations }\end{array}$ & $\begin{array}{c}\text { General } \\
\text { Practitioner } \\
\text { Agreement }\end{array}$ & $\begin{array}{c}\text { Percentage of } \\
\text { implementation } \\
\text { of pharmacists } \\
\text { recommendation }\end{array}$ \\
\hline Decrease dose & 21 & 19 & $90.47 \%$ \\
Increase dose & 37 & 28 & $75.67 \%$ \\
Overall & 58 & 47 & 81.03 \\
\hline
\end{tabular}

not attached to medical practitioners and the pharmacists have hesitations and lack of confidence or motivation to do anticoagulation therapy monitoring service.

\section{CONCLUSION}

This study proved that improved pharmacists knowledge can improve patient quality of life by reducing treatment related distress. This study paved the way for a larger study by incorporating more number of community pharmacists and medical practitioners into anticoagulant 
therapy management services. More and more awareness about such services shall be created among pharmacists, physicians and patients by using the model demonstrated in this study.

\section{ACKNOWLEDGEMENT}

Authors wish to thank the community pharmacies and pharmacists who actively participated in the study and logistic and technical support given by the participating community pharmacies of Tamil Nadu

\section{CONFLICT OF INTEREST}

The authors declare no conflict of interest.

\section{ABBREVIATIONS}

INR: International Normalized Ratio; HSE: Health Services Executive; CPE: Continuing Professional Education.

\section{REFERENCES}

1. Cardiovascular Drug Guidelines, Edition 3. Therapeutics Committee, Victorian Medical Postgraduate Foundation Inc. 2003.

2. Daniel M, Clark NP, Kaatz S, Schnurr T, Ansell JE. Guidance for the practical management of warfarin therapy in the treatment of venous thromboembolism. J Thromb Thrombolysis. 2016;41(1):187-205.

3. Suzuki S, Yamashita T, Kato T, Fujino T, Sagara K, Sawada H, et al. Incidence of major bleeding complication of warfarin therapy in Japanese patients with atrial fibrillation. Circ J. 2007;71(5):761-5.

4. Ouirke W, Cahill MR, Perera K, Sargent J, Conway J. Warfarin prevalence, indications for use and haemorrhagic events. Ir Med J. 2007;100:402-4.
5. Runciman WB, Webb RK, Helps SC, et al. A comparison of iatrogenic injury studies in Australia and the USA II: Reviewer behaviour and quality of care. Int J Qual Health Care. 2000;12(5):379-88.

6. Second National Report on Patient Safety - Improving Medication Safety, Australian Council for Safety and Quality in Health Care. 2002.

7. Chan E, McLachlan AJ, O'Reilly RA, Rowland M. Stereochemical aspects of warfarin drug interactions: Use of a combined pharmacokinetic-pharmacodynamic model. Clin Pharmacol Ther. 1994;56(3):286-94.

8. McLachlan A. Warfarin drug interactions. Australian Pharmacist. 2000;19:38-46.

9. Campbell P, Roberts G, Eaton V, Coghlan D, Gallus A. Managing warfarin therapy in the community. Australian Prescriber. 2001;24:86-9.

10. Lane D, Lip GY. Anti-thrombotic therapy for atrial fibrillation and patients' preferences for treatment. Age Ageing. 2005;34:1-3.

11. Das AK, Willcoxson P, Corrado OJ. Does long-term warfarin affect the quality of life of older people?. Age Ageing. 2005;34(3):312-3.

12. Baker JW, Pierce KL, Ryals CA. INR goal attainment and oral anticoagulation knowledge of patients enrolled in an anticoagulation clinic in a Veterans Affairs medical center. J Manag Care Pharm. 2011;17(2):133-42.

13. Sawicki PT. A structured teaching and self-management program for patients receiving oral anticoagulation: A randomized controlled trial. Working Group for the study of patient self -management of Oral Anticoagulation. JAMA. 1999;281(2):145-50.

14. Samsa GP, Matchar DB. Relationship between test frequency and outcomes of anticoagulation: A literature review and commentary with implications for the design of randomized trials of patient's self-management. JThromb Thrombolysis. 2000;9(3):283-92

15. Bajorek BV. "Stroke prevention in elderly patients with atrial fibrillation." [Thesis] Faculty of Pharmacy, University of Sydney. 2002.

16. Winans AR, Rudd KM, Triller D. Assessing anticoagulation knowledge in patients new to warfarin therapy. Ann Pharmacother. 2010;44(7-8):1152-7.

17. Lakshmi R, James E, Kirthivasan R. Study on impact of clinical pharmacist's interventions in the optimal use of oral anticoagulants in stroke patients. Indian J Pharm Sci. 2013;75(1):53-9. 